\title{
Features of the Immune System Functioning with Persistence of Infectious Agents in Women with Chronic Endometrial Inflammation and Reproductive Disorders
}

\author{
Irina N. Danusevich, $\mathrm{PhD}^{*}$; Eldar M. Sharifulin; Uliana M. Nemchenko, $\mathrm{PhD}$; \\ Lyubov I. Kolesnikova, $\mathrm{PhD}, \mathrm{ScD}$, Member of the RAS \\ Scientific Centre for Family Health and Human Reproduction Problems \\ Irkutsk, the Russian Federation
}

\begin{abstract}
The objective of our study was to investigate the specific features of immune status indicators in women of reproductive age with chronic endometritis (CE) and reproductive disorders.

Methods and Results: The observational study involved 81 women of reproductive age with reproductive disorders. The main group (MG) included 50 women with CE (mean age of 29.2 \pm 5.34 years). The control group (CG) consisted of 31 fertile women also of reproductive age(mean age of $30.7 \pm 5.9$ years). MG was divided into the following subgroups: Subgroup A(SubA) included 31 patients with verified CE and an isolated infectious agent from endometrial tissue: Subgroup B (SubB) included 19 patients with verified CE and the absence of an infectious agent in the endometrial tissue. Endometrial aspiration pipe biopsy was performed on days 4-9 of the menstrual cycle (middle proliferative phase) using a disposable intrauterine probe (Taizhou Kechuang Medical Apparatus Co., Ltd, China) followed by histological examination of endometrial tissue. Laboratory diagnostics for sexually transmitted infections (STIs) was performed using the bacterial culture method. For the diagnosis of viral infection (HPV, HSV, CMV), cervical samples were studied using PCR. If STIs were detected, the patients were excluded from further research. Ultrasound examination of the pelvic organs was performed using the Aloka-5500 device with a $7 \mathrm{MHz}$ vaginal probe in two-dimensional visualization mode. The concentration of cytokines (IL-1 $\beta$, INF- $\gamma$, TNF- $\alpha$, ILs-4,6,8,10) in the endometrium was determined using the Protein Contour test systems (Russia) and Multiskan EX ELISA Analyzer (Germany). The percentages and absolute counts of blood lymphocytes (CD3+, CD3+/CD8+/CD45+, CD19+/CD45+, and CD16+/CD56+/CD45+ cells) were determined by the method of indirect immunofluorescence with monoclonal antibodies using the BD FACSCalibur flow cytometer (USA).

We found a significant increase in the blood concentrations of CD3+ cells, CD3+/CD8+/CD45+ cells, and CD19+/CD45+ cells and a decrease in the levels of CD16+/CD56+/CD45+ cells, microbicidal activity of oxygen-dependent function of neutrophils, and phagocytic activity of neutrophils, as well as a significant decrease in the levels of IgA, IgM, and IRI in MG, compared to CG. In SubA, compared to SubB, we found a significant decrease in CD3+ cells and CD19+/C45+ cells and a slight increase in immunoregulatory index. The concentrations of tissue cytokines in women of MG were characterized by a 3-fold increase in the level of pro- and antiinflammatory cytokines (IL-1 $\beta$, ILs - 4, 6, 10, and INF- $\gamma$ ), and a 4-fold increase in the levels of TNF- $\alpha$ and IL-8, compared to CG. In SubA, in comparison with SubB, a significant decrease in anti-inflammatory cytokines (ILs-4,10) and chemokine IL-8 was revealed against the background of a significant increase in the concentrations of INF- $\gamma$.

Conclusion: The results obtained indicate changes in the reactivity of the immune system in women with reproductive disorders and chronic inflammation in the endometrium. The most pronounced changes in the local immunity indicators are observed when opportunistic pathogens are detected in the endometrial tissue.(International Journal of Biomedicine. 2020;10(4):362-368.)
\end{abstract}

Key Words: chronic endometritis $\bullet$ immunity $\bullet$ reproductive disorders

\section{Abbreviations}

CE, chronic endometritis; CIC, circulating immune complexes; NBT-test, nitroblue tetrazolium test; HSV, herpes simplex virus, IL, interleukin; IRI, immunoregulatory index; OPs, opportunistic pathogens; STIs, sexually transmitted infections; PCR, polymerase chain reaction; NK, natural killer. 


\section{Introduction}

Chronic endometritis (CE) is a poorly understood pathology. The high risk of reproductive dysfunctions, and complicated pregnancy and childbirth, in CE determines the need for a comprehensive study of this pathology. CE is mainly found in women of reproductive age, where its frequency ranges from $3 \%$ to $73 \%{ }^{(1-3)}$ Patients with a chronic, oligosymptomatic inflammatory process in the small pelvis are particularly challenging for diagnosis and treatment. Evaluation of clinical manifestations revealed the absence of any clinical symptoms of CE in $35 \%-40 \%$ of patients. ${ }^{(4)}$ It should be noted that the information content of using the minimum criteria for the diagnosis of pelvic inflammatory disease, which were proposed by the CDC (USA, 1993), in cases of CE is observed only in $33 \%$. $^{(4,5)}$

Traditional treatment regimens have not been very effective; according to some authors, their effectiveness does not exceed $58 \%-67 \% .^{(6-9)}$ Prescribing antibiotics to patients with sluggish forms of $\mathrm{CE}$ is equated with drug aggression. In the absence of a proven persistence of a causally significant infectious agent, starting treatment with antimicrobial drugs is not recommended, since histologically proven chronic endometritis is based on the autoimmune nature of inflammation. ${ }^{(10)}$ A number of studies have shown that the use of routine diagnostic methods does not allow identifying an etiological factor in $40 \%-70 \%$ of cases of CE. ${ }^{(11,12)}$

Infection is the basis of CE. Cicinelli et al. ${ }^{(13)}$ analyzed 438 cases of hysteroscopically diagnosed $\mathrm{CE}$, and reported that $73.1 \%$ exhibited $\geq 1$ positive pathogen finding. Most commonly, $\mathrm{CE}$ is provoked by Enterococcus faecalis, Enterobacteriaceae, Streptococcus spp., Staphylococcus spp., Gardnerella vaginalis, and Mycoplasma spp., as well as genital pathogens associated with STIs (Ur. urealyticum, Chl. trachomatis, and Neisseria gonorrhoeae). Interactions between infectious agents and the endometrial environment are a major concern in the treatment of infertility, miscarriage, and preterm labor. ${ }^{(14)}$ The main issue of $\mathrm{CE}$ requiring study is the interaction between microorganisms and endometrial immunity rather than just the presence of microorganisms in the endometrium.

In a study performed by Matteo et al., the secretory endometrium of infertile women with $\mathrm{CE}$ displayed a significantly lower percentage of $\mathrm{CD} 56+\mathrm{CD} 16-$ and of CD56(bright) CD16- cells (47.8\% vs. $30.1 \%$ and $79.5 \%$ vs. $67.3 \%$, respectively; $P<0.01$ ) than a group of patients without $\mathrm{CE}$, while the percentage of $\mathrm{CD} 3+$ cells was significantly higher $(25 \%$ vs. $10.5 \%$; $P<0.01) .{ }^{(15)}$ Kitaya and Yasuo ${ }^{(16)}$ reported that lymphocyte $\mathrm{B}$ cell levels were elevated in the endometrium of patients with $\mathrm{CE}$, and they also observed the abnormal expression of paracrine mediators, such as adhesion molecules and chemokines. Tortorell et al. found that IL-6, IL-1 $\beta$, and TNF- $\alpha$ levels were markedly higher in menstrual effluents of infertile women with CE than in those of control subjects. ${ }^{(17)}$

Complex interactions between the endocrine and immune systems govern the key endometrial events of implantation and menstruation. In contrast to other tissue sites, cyclical endometrial inflammation is physiological. However, dysregulation of this inflammatory response in the presence of opportunistic pathogens can lead to endometrial disorders. ${ }^{(4,6,18-22)}$

The objective of our study was to investigate the specific features of immune status indicators in women of reproductive age with $\mathrm{CE}$ and reproductive disorders.

\section{Materials and Methods}

The observational study involved 81 women of reproductive age with reproductive disorders. The main group (MG) included 50 women with CE (mean age of 29.2 \pm 5.34 years). The control group (CG) consisted of 31 fertile women also of reproductive age(mean age of $30.7 \pm 5.9$ years).

MG was divided into the following subgroups:

- Subgroup A (SubA) included 31 patients with verified $\mathrm{CE}$ and an isolated infectious agent from endometrial tissue.

- Subgroup B (SubB) included 19 patients with verified CE and the absence of an infectious agent in the endometrial tissue.

The criteria for inclusion in MG were the absence of pregnancy in regular sex life without contraception for a year or more or miscarriage during the last year, the diagnosis of $\mathrm{CE}$ verified by a histopathological examination. Exclusion criteria were the presence of causes for reproductive disorders: endocrine, genetic, hemostasiological, and immunological disorders, including male infertility.

The patients were examined according to the standards of infertility examination, including questionnaires, as well as general clinical, gynecological, and laboratory instrumental examinations. Endometrial aspiration pipe biopsy was performed on days 4-9 of the menstrual cycle (middle proliferative phase) using a disposable intrauterine probe (Taizhou Kechuang Medical Apparatus Co., Ltd, China) followed by histological examination of endometrial tissue. Laboratory diagnostics for STIs $(\mathrm{N}$. gonorrhoeae, T. vaginalis, Ur. urealyticum, M. hominis, M. Genitalium. Chl. trachomatis) was performed using the bacterial culture method. For the diagnosis of viral infection (HPV, HSV, CMV), cervical samples were studied using PCR. If STIs were detected, the patients were excluded from further research. Microbiological studies of the vaginal biotope were carried out in accordance with the guidelines for research methods used in clinical and diagnostic laboratories of medical and preventive institutions. Ultrasound examination of the pelvic organs was performed using the Aloka-5500 device with a $7 \mathrm{MHz}$ vaginal probe in two-dimensional visualization mode. The concentration of cytokines (IL- $1 \beta$, INF- $\gamma$, TNF- $\alpha$, ILs-4,6,8,10) in the endometrium was determined using the Protein Contour test systems (Russia) and Multiskan EX ELISA Analyzer (Germany).

The percentages and absolute counts of blood lymphocytes (CD3+, CD3+/CD8+/CD45+, CD19+/CD45+, and $\mathrm{CD} 16+/ \mathrm{CD} 56+/ \mathrm{CD} 45+$ cells) were determined by the method of indirect immunofluorescence with monoclonal antibodies using the BD FACSCalibur flow cytometer (USA).

The study was carried out in compliance with Ethical Principles for Medical Research Involving Human Subjects, Adopted by the 18th WMA General Assembly, Helsinki, Finland, June 1964, and amended by the 64th WMA General Assembly, Fortaleza, Brazil, October 2013. The study was 
approved by the Ethics Committee of the Scientific Center for Family Health and Human Reproduction Problems. Written informed consent was obtained from each patient.

Statistical processing was carried out using the STATISTICA Version 10 (StatSoft, USA). The normality of distribution of continuous variables was tested by Shapiro-Wilk test. The mean (M) and standard error of the mean (SEM) were calculated. The Mann-Whitney U-Test was used to compare differences between two independent groups. Group comparisons with respect to categorical variables are performed using chisquare test. Spearman's rank correlation coefficient was calculated to measure the strength and direction of the relationship between two variables. A value of $P<0.05$ was considered significant.

\section{Results}

In the medical history of the MG women, compared to CG, there were significantly higher cases of trichomoniasis $(P=0.000)$, Chlamydia $(P=0.000)$, ureaplasmosis $(P=0.001), \operatorname{HSV}(P=0.014)$, and candidiasis $(P=0.03)$. In the structure of concomitant pathology, ENT (Ear, Nose, and Throat) disorders $(P=0.04)$, kidney diseases $(P=0.002)$, gastrointestinal disease $(P=0.002)$, and allergic diseases $(P=0.001)$ were diagnosed more often in MG.

In MG, a high frequency of opportunistic pathogens (OPs) was observed both in the cervical canal and in the endometrium. The detection rate of OPs in the cervical canal was $42 \%$. Monoinfection was found in $8 \%$ of cases; a mixed infection with a predominance of an association of three types of microorganisms was found in $34 \%$ of cases. The number of microorganisms was in the range of $10^{4}-10^{6} \mathrm{CFU} / \mathrm{ml}$. The following OPs were isolated from the cervical canal: Ur. urealyticum (22\%), coagulase-negative staphylococci (mainly S. epidermidis - 18\%) with pronounced pathogenic properties in the form of hemolytic activity, and fungi of the genus Candida (18\%0, Proteus (16\%), and E.coli (10\%). Among viral infections, CMV, HSV, and high-risk HPV were identified in $8 \%$ for each pathogen. In CG, Ur. urealyticum, Candida, E. coli, M. hominis, Streptococcus, Citrobacter spp., Enterococcus faecalis, and low-risk HPV were detected as monoinfection in isolated cases.

The detection rate of microflora in the endometrium was $60 \%$ : monoinfection in $12 \%$ of cases and the presence two or three types of microorganisms in $48 \%$. The number of microorganisms was in the range of $10^{4}-10^{6} \mathrm{CFU} / \mathrm{ml}$. The species diversity of the endometrial microflora was represented by the groups of enterococci (E.coli - 28\%, Enterococcus faecalis - 16\%, Bacteroides spp. - 8\%), staphylococci (Staphylococcus epidermidis - 18\%, Staphylococcus haemolyticus - 8\%, Staphylococcus aureus - $8 \%$ ) and Streptococcus in $4 \%$ of cases, and by the absence of these pathogens in the control group.

Table 1.

The parameters of the cellular and humoral immune response in patients of study groups

\begin{tabular}{|l|c|c|c|c|}
\hline \multirow{2}{*}{ Immunity indicators } & $\mathrm{MG}(\mathrm{n}=50)$ & SubA $(\Pi=31)$ & SubB $(\Pi=19)$ & $\mathrm{CG}(\mathrm{n}=31)$ \\
\cline { 2 - 5 } & 1 & $1 / \mathrm{a}$ & $1 / \mathrm{b}$ & 2 \\
\hline CD3+/CD45+ & $72.56 \pm 7.5$ & $72.53 \pm 8.7$ & $72.33 \pm 7.6$ & $71.09 \pm 4.6$ \\
\hline CD3+ & $1693 \pm 338.4^{*}$ & $2254.52 \pm 373.5^{\wedge}$ & $2574.73 \pm 202.9$ & $1462 \pm 348.4$ \\
\hline CD3+CD8+/CD45+ & $28.6 \pm 4.8^{*}$ & $27.64 \pm 4.5$ & $28.44 \pm 4.7$ & $22.25 \pm 3.4$ \\
\hline CD3+CD4+/CD45+ & $43.1 \pm 5.4$ & $45.11 \pm 0.2$ & $43.29 \pm 5.6$ & $45.93 \pm 5.3$ \\
\hline CD3+CD4+CD8+/CD45+ & $0.80 \pm 0.11$ & $0.64 \pm 0.7$ & $0.81 \pm 0.8$ & $0.74 \pm 0.17$ \\
\hline CD16+56+/CD45+ & $12 \pm 4.7^{*}$ & $12.17 \pm 5.2$ & $12.14 \pm 4.7$ & $13.6 \pm 4.7$ \\
\hline CD19+/CD45+ & $18 \pm 5.9^{*}$ & $11.88 \pm 2.1^{\wedge}$ & $15.14 \pm 2.6$ & $12.13 \pm 3.4$ \\
\hline Phagocytosis & $52.6 \pm 10.4^{*}$ & $52.70 \pm 11.4$ & $52.60 \pm 10.6$ & $61.45 \pm 8.3$ \\
\hline NBT-test spon. & $5.4 \pm 3.2^{*}$ & $5.35 \pm 3.5$ & $5.31 \pm 3.2$ & $9.29 \pm 7.7$ \\
\hline NBT-test ind. & $28 . \pm 11.2$ & $29.29 \pm 10.2$ & $28.87 \pm 11.4$ & $32.35 \pm 11.8$ \\
\hline IgG, g/1 & $13.4 \pm 5.7$ & $13.73 \pm 6.0$ & $13.36 \pm 5.8$ & $14.26 \pm 4.2$ \\
\hline IgA, g/1 & $1.46 \pm 0.8^{*}$ & $1.47 \pm 0.8$ & $1.48 \pm 0.8$ & $2.3 \pm 1.1$ \\
\hline IgM, g/1 & $2.0 \pm 0.9^{*}$ & $1.90 \pm 0.9$ & $2.00 \pm 0.9$ & $2.6 \pm 0.8$ \\
\hline CIC & $37.0 \pm 11.1$ & $36.11 \pm 11.1$ & $37.10 \pm 1.3$ & $40.74 \pm 14.1$ \\
\hline IRI $(C D 4+/ C D 8+)$ & $1.5 \pm 0.5^{*}$ & $1.68 \pm 0.7$ & $1.55 \pm 0.6$ & $2.12 \pm 0.4$ \\
\hline
\end{tabular}

$* P_{1-2}<0.05, \wedge P_{1 / a-1 / b}<0.05$

Table 2.

The levels of cytokines in the endometrial tissue in patients of study groups

\begin{tabular}{|l|c|c|c|c|}
\hline \multirow{2}{*}{ Indicators of local immunity } & $\mathrm{MG}(\mathrm{n}=50)$ & SubA $(\Pi=31)$ & SubB $(\Pi=19)$ & $\mathrm{CG}(\mathrm{n}=31)$ \\
\cline { 2 - 5 } & 1 & $1 / \mathrm{a}$ & $1 / \mathrm{b}$ & 2 \\
\hline IL-1 $\beta, \mathrm{pg} / \mathrm{ml}$ & $64.9 \pm 6.25^{*}$ & $64.97 \pm 39.25$ & $62.85 \pm 43.54$ & $23.64 \pm 3.37$ \\
\hline IL-4, $\mathrm{pg} / \mathrm{ml}$ & $38 \pm 15.5^{*}$ & $22.38 \pm 20.12^{\wedge}$ & $38.22 \pm 13.71$ & $13.71 \pm 1.93$ \\
\hline IL-6, $\mathrm{pg} / \mathrm{ml}$ & $87.1 \pm 9.98^{*}$ & $85.32 \pm 39.91$ & $87.00 \pm 71.15$ & $39.53 \pm 3.81$ \\
\hline $\mathrm{IL}-8, \mathrm{pg} / \mathrm{ml}$ & $110.6 \pm 10.3^{*}$ & $92.82 \pm 48.24^{\wedge}$ & $112.98 \pm 12.80$ & $23 \pm 2.42$ \\
\hline IL-10, $\mathrm{pg} / \mathrm{ml}$ & $53.1 \pm 7.0^{*}$ & $38.67 \pm 39.46^{\wedge}$ & $51.34 \pm 51.35$ & $26.67 \pm 4.61$ \\
\hline INF- $\gamma, \mathrm{pg} / \mathrm{ml}$ & $53.82 \pm 4.38^{*}$ & $100.65 \pm 76.29^{\wedge}$ & $73.46 \pm 65.33$ & $25.75 \pm 4.24$ \\
\hline TNF- $\alpha, \mathrm{pg} / \mathrm{ml}$ & $48.5 \pm 7.27^{*}$ & $58.00 \pm 54.25$ & $48.17 \pm 53.34$ & $9.48 \pm 0.85$ \\
\hline
\end{tabular}

$* P_{1-2}<0.05, \wedge P_{1 / a-1 / b}<0.05$ 
The immunity parameters in patients of both study groups are presented in Tables 1-2. We found a significant increase in the blood concentrations of CD3+ (T cells), CD3+/CD8+/ CD45+ (total T cells and suppressor/cytotoxic T-lymphocytes), and CD19+/CD45+ B cells and a decrease in the levels of CD16+/CD56+/CD45+ (NK cells), microbicidal activity of oxygen-dependent function of neutrophils, and phagocytic activity of neutrophils, as well as a significant decrease in the levels of $\operatorname{IgA}$, IgM, and IRI in MG, compared to CG. In SubA, compared to SubB, we found a significant decrease in CD3+ T-lymphocytes and CD19+/C45+ B-lymphocytes and a slight increase in IRI.

The levels of cytokines produced by immunocompetent cells were determined in the endometrial tissue (Table 2). The concentrations of tissue cytokines in women of MG were characterized by a 3 -fold increase in the level of pro- and antiinflammatory cytokines (IL-1 $\beta$, ILs - 4, 6, 10, and INF- $\gamma$ ), and a 4-fold increase in the levels of TNF- $\alpha$ and IL-8, compared to CG.

In SubA, in comparison with SubB, a significant decrease in anti-inflammatory cytokines (ILs-4,10) and chemokine IL-8 was revealed against the background of a significant increase in the concentrations of INF- $\gamma$.

Correlation analysis revealed an inverse correlation between $\mathrm{T}$ lymphocytes and $\mathrm{B}$ lymphocytes $(\mathrm{r}=-0.40)$ in $\mathrm{MG}$, compared to a direct correlation in $\mathrm{CG}(\mathrm{r}=0.61)$. In $\mathrm{MG}$, we found the appearance of new correlations between NK cells and NBT-test spontaneous $(\mathrm{r}=-0.51)$, and between phagocytosis and NBT-test induced $(\mathrm{r}=0.67)$, as well as weak negative correlations between IL-1 and CD3+ lymphocytes $(\mathrm{r}=-0.28)$ and NBT-test spontaneous $(\mathrm{r}=-0.32)$. Weak negative correlations were also found between INF- $\gamma$ and NK cells $(r=-0.28)$, IL-4 and CIC $(\mathrm{r}=-0.39)$. IL-4 positively correlated with CD19+ lymphocytes $(\mathrm{r}=0.32)$. At the same time, a negative correlation was found between IL-10 and CD19+ lymphocytes $(\mathrm{r}=-0.19)$ and positive correlations between IL-10 and $\operatorname{IgA}(r=0.35)$ and $\operatorname{IgM}(r=0.34)$.

\section{Discussion}

A definitive diagnosis of $\mathrm{CE}$ can only be made histologically and is noted by the presence of multiple plasma cells in the endometrial stromal area. ${ }^{(23-26)}$ In this connection, CE may describe the condition in which immune cells monitor some aberrant pathogens, which reside in the uterine cavity for a long period, and regulate them to prevent the progression to intense inflammation. ${ }^{(27,28)}$ It is possible that $\mathrm{CE}$ is a state with old inflammation after acute endometritis. ${ }^{(29,30)}$

In $\mathrm{CE}$ women with infertility, we revealed the activation of cellular immunity (a significant increase in the blood concentrations of $\mathrm{CD} 3+, \mathrm{CD} 3+\mathrm{CD} 8+/ \mathrm{CD} 45+$, and $\mathrm{CD} 19+/$ CD45+ cells and a decrease in the levels of CD16+CD56+/ CD45+ cells, microbicidal activity of oxygen-dependent function of neutrophils, and phagocytic activity of neutrophils, and IRI), in comparison with CG women.

Regarding humoral immunity, there was a significant decrease in IgA and IgM, which are necessary for maintaining the first line of immune defense of the mucous membranes from viral infection $(P<0.05) .{ }^{(31)}$ These data correlate with information about the absence of intersystem connections with the parameter of total phagocytosis activity that indicates an imbalance in the protective systems. A decrease in the oxygendependent function of neutrophils (NBT-test spontaneous) confirms the chronicity of the inflammatory process. ${ }^{(32)}$

The role of $\operatorname{IgA}$ in the immune defense is largely determined by its interaction with immunocompetent cells that carry out cell-mediated defense reactions(phagocytosis, cytotoxic effects, etc.). ${ }^{(33)}$ It has been shown that there is a direct relationship between the activity of phagocytosis and the resistance of the organism to infection: the more active the phagocytosis in relation to microbes, the more pronounced the immunity to them, and vice versa. ${ }^{(34)}$

It is known that some stages of phagocytosis can be actively suppressed by microbes or be defective as a result of genetic disorders, which in both cases leads to the inability to effectively remove microorganisms and, as a result, chronic inflammation. The results obtained indicate a decrease in the functional activity of the immune system, reflecting the secondary immunodeficiency state, and are more characteristic of a chronic sluggish inflammatory process with reduced antiviral protection from the mucous membranes.

An additional antigenic load in the verified $\mathrm{CE}$ with OPs leads to the activation of antigen-specific mechanisms of the immune response with the formation of further autoimmune reactions. An increase in the expression of all studied cytokines (IL-1 $\beta$, IL-4, 6,10 , INF- $\gamma$, TNF- $\alpha$, IL-8) in $\mathrm{CE}$ women, in comparison with $\mathrm{CG}$, indicates the activation of immunocompetent cells in response to the formed chronic inflammation. ${ }^{(34-36)}$ It is believed that a high concentration of IL-1 affects the systemic inflammatory response by inducing the synthesis of serum amyloid $\mathrm{P}$ in the liver that subsequently leads to the stimulation of IL- 6 and the production of neutrophils in the bone marrow. ${ }^{(37)}$

Moreover, IL-1 also modulates the secretion of prostaglandins in the endometrium. Endometrial cells respond to the presence of bacteria by producing prostaglandins, in particular prostaglandin E2. ${ }^{(38,39)}$ In addition, IL-1 in the endometrial tissue promotes the formation of endotoxin by bacteria and viruses and increases degranulation processes.

IL-6 is a pleiotropic cytokine that regulates multiple biological processes, including the development of inflammation, immune responses, and the acute phase of chronic process exacerbation. ${ }^{(32)}$ IL-6 also plays an important role in the processes of chronic inflammation, in particular, in infectious processes of bacterial etiology; it also participates in the activation of specific antibody synthesis in the second phase of the immune response. ${ }^{(32)}$

IL-8 enhances the directed migration of leukocytes to the inflammatory focus and, together with other cytokines, increases their functional activity aimed at eliminating pathogens. ${ }^{(40)}$ At the same time, pro-inflammatory cytokines activate the metabolism of connective tissue and stimulate the proliferation of fibroblasts and epithelial cells necessary for healing and restoring tissue integrity.

An increase in the level of IL-4 affects the activity of NK cells of the endometrium and reflects the activity of the humoral immune response and the synthesis of antibodies by increasing the level of sIgA. ${ }^{(33,40)} \mathrm{IL}-4$ is one of the key inducers 
of the development of an autoimmune response; it is involved in the development of proliferative and fibrotic processes.

The results obtained in our study indicate changes in the immune response that are characteristic of inflammation in $\mathrm{CE}$ women. It is well known that the power of the immune response is determined by the antigen load. ${ }^{(35,41)}$ In the presence of OPs, we noted the more pronounced changes in the local immune response. The presence of an infectious agent in the endometrium was characterized by multidirectional changes in cytokine levels, which were expressed by a significant increase in the concentration of TNF- $\alpha$ and INF- $\gamma$ and by a significant decrease in ILs-4,10 and IL-8 $(P<0.05)$. It is known that an increased immune response during the presence of an infectious agent is associated with a higher level of mRNA expression encoding TLR4 and TLR2, which recognize bacterial LPS and lipopeptides, respectively, as mechanisms of bacterial persistence. ${ }^{(42-44)}$

In the $\mathrm{CE}$ endometrium, there was a significant (1.5fold) increase in the concentration of INF- $\gamma$, relative to the data obtained in $\mathrm{CG}(P<0.05)$. INF- $\gamma$ is the most important endogenous immunomodulator necessary for the development of a specific immune response. It is known that in the late stages of acute inflammation and in chronic inflammation, INF- $\gamma$ enhances the secretion of antibodies, including autoreactive ones. ${ }^{(45,46)}$ Fournier and Philpott ${ }^{(47)}$ showed that several innate immunity receptors may be implicated in host defense against S.aureus. The ability of peptidoglycan and lipoteichoic acid isolated from Staphylococcus aureus to induce the release of TNF- $\alpha$, IL- 6 , and IL- 10 by $\mathrm{T}$ cells and monocytes was determined by Wang et al. ${ }^{(48)}$ In turn, sIgA and INF- $\gamma$ are associated with the level of TNF- $\alpha$, which is one of the key cytokines in implementing the antiviral immune response, as well as in regulating the intensity of inflammation and the effectiveness of immune defense. . $^{(32,34)}$ There is a study showing the inhibitory effect of TNF- $\alpha$ on the growth of HSV-infected cells, which is enhanced by the action of INF- . $^{(49)}$

A pronounced increase in the chemokine genes, found after E.coli inoculation, can lead to the recruitment of neutrophils, monocytes, and T-lymphocytes. ${ }^{(38,50)}$ We noted a decrease in IL- 8 and the microbicidal activity of neutrophils $(P<0.05)$. This indicates that the neutrophil impact is insufficient, the development of an adequate immune response is slowed down, and therefore the infectious agent that contributes to its persistence is not fully suppressed.

Pro-inflammatory reactions, in order to avoid excessive immune activation by bacteria, including the effects of IL-1, TNF- $\alpha$, and IL-6, depend on anti-inflammatory mediators such as IL-10, transforming factor $1-\beta$, and prostaglandin E2. ${ }^{(46,51,52)}$

Some researchers have shown that genes for antiinflammatory cytokines (IL-10 and IL-13) were expressed at very low levels and there was no significant increase in them in the absence of infection, while the expression of these cytokines increased in response to E.coli invasion. This activity of antiinflammatory cytokines prepares the immune response for rapid suppression of pro-inflammatory cytokines to prevent an excessive inflammatory response. ${ }^{(15,53)}$

A decrease in ILs-4,10 in response to the activity of an infectious agent in our study indicates the development of an inadequate, pronounced, local inflammatory reaction in the endometrial tissue with a deficiency of anti-inflammatory cytokines, which may be one of the mechanisms of long-term persistence of the infection in the endometrial tissue.

The presence of a persistent infection characterizes a decrease in the organism's resistance to colonization. It determines the outcome of inflammation (infection). Its decrease is caused by factors that lead to changes in the normoflora - the activity of OPs and/or a decrease in the number of lactobacilli. It is possible that the isolated OPs from the endometrium have an anti-lactoferrin activity, which is the mechanism for maintaining their existence and persistence. According to some studies, the maximum percentage of women with "deep dysbiosis," when the density of lactobacilli is insignificant or not registered by cultural methods, was observed in $49 \%$ of women with chronic pelvic inflammatory diseases. In $53 \%$ of women with infertility and miscarriage, the complete absence of lactobacilli was also observed. $^{(54)}$

In conclusion, the results obtained indicate changes in the reactivity of the immune system in women with reproductive disorders and chronic inflammation in the endometrium. The most pronounced changes in the local immunity indicators are observed when opportunistic pathogens are detected in the endometrial tissue.

\section{Competing Interests}

The authors declare that they have no competing interests.

\section{References}

1. Korsak VS, Zabelkina OV, Isakova EV, Popov EN. [Diagnosis of pathology of the uterine cavity in patients suffering from tubal-peritoneal infertility]. Journal of Obstetrics and Women's Diseases. 2005;54(3):50-53. [Article in Russian]. 2. Kiryushchenkov PA, Belousov DM, Veryasov VN, Menzhinskaya IV, Alekseeva MS. [Significance of uterine pathology and peculiarities of pre-gestational preparation of women with the syndrome of habitual early pregnancy loss]. Journal of Obstetrics and Gynecology. 2009;5:15-19. [Article in Russian].

3. Rudakova EB, Luzin AA, Bogdanova ON, Mozgovoy SI, Loboda OA, Pilipenko MA, et al. [Chronic endometritis: from improving the diagnostic approach to optimizing treatment]. Lechaschi Vrach. 2008;10:6-10. [Article in Russian].

4. Eckert LO, Hawes SE, Wölner-Hanssen PK, Kiviat NB, Wasserheit JN, Paavonen JA, et al. Endometritis: the clinicalpathologic syndrome. Am J Obstet Gynecol. 2002;186(4):6905. doi: $10.1067 / \mathrm{mob} .2002 .121728$.

5. Campos-Outcalt D. CDC update: Guidelines for treating STDs. J Fam Pract. 2011 Mar;60(3):143-6.

6. Dubnitskaya LV, Nazarenko TA. [Chronic endometritis: diagnostic and treatment options]. Consilium Medicum. 2007;9(6):25-28. [Article in Russian].

7. Zdanovskiǐ VM, Buravchenko NB. [Results of using assisted reproductive technologies in infertile patients with endometrial pathology]. Russian Bulletin of ObstetricianGynecologist. 2010;10(2):39-42. [Article in Russian].

8. Kulakov VI, Ankirskaya AS, Beloborodov SM. [Antibacterial therapy of inflammatory diseases of the pelvic organs: tasks, solutions, mistakes]. Gynecology. 2004;7:3-5. 
[Article in Russian].

9. Rudakova EB, Besman IV. [Assisted reproductive technologies. Problems of pregnancy loss]. Lechaschi Vrach. 2010;3:46-49. [Article in Russian].

10. Radzinsky VE, Kozlov RS, Dukhin AO. Antibacterial therapy of pelvic inflammatory diseases without mistakes and experiments: a methodological guide for doctors. M.: StatusPraesens, 2013:16. [In Russian].

11. Sidelnikova VM, Sukhikh GT. Miscarriage: A Guide for Physicians. M., 2011:534. [In Russian].

12. Andrews WW, Hauth JC, Cliver SP, Conner MG, Goldenberg RL, Goepfert AR. Association of asymptomatic bacterial vaginosis with endometrial microbial colonization and plasma cell endometritis in nonpregnant women. Am J Obstet Gynecol. 2006;195(6):1611-6. doi: 10.1016/j.ajog.2006.04.010. 13. Cicinelli E, De Ziegler D, Nicoletti R, Colafiglio G, Saliani $\mathrm{N}$, Resta L, et al. Chronic endometritis: correlation among hysteroscopic, histologic, and bacteriologic findings in a prospective trial with 2190 consecutive officehysteroscopies. Fertil Steril. 2008;89(3):677-84. doi: 10.1016/j.fertnstert.2007.03.074.

14. Eckert LO, Moore DE, Patton DL, Agnew KJ, Eschenbach DA. Relationship of vaginal bacteria and inflammation with conception and early pregnancy loss following in-vitro fertilization. Infect Dis Obstet Gynecol. 2003;11(1):11-7. doi: 10.1155/S1064744903000024.

15. Matteo M, Cicinelli E, Greco P, Massenzio F, Baldini D, Falagario T, et al. Abnormal pattern of lymphocyte subpopulations in the endometrium of infertile women with chronic endometritis. Am J Reprod Immunol. 2009 May;61(5):322-9. doi: 10.1111/j.1600-0897.2009.00698.x.

16. Kitaya K, Yasuo T. Immunohistochemistrical and clinicopathological characterization of chronic endometritis. Am J Reprod Immunol. 2011 Nov;66(5):410-5. doi: 10.1111/j.16000897.2011.01051.x.

17. Tortorella C, Piazzolla G, Matteo M, Pinto V, Tinelli $\mathrm{R}$, Sabbà $\mathrm{C}$, et al. Interleukin-6, interleukin-1 $\beta$, and tumor necrosis factor $\alpha$ in menstrual effluents as biomarkers of chronic endometritis. Fertil Steril. 2014 Jan;101(1):242-7. doi: 10.1016/j.fertnstert.2013.09.041.

18. Maybin JA, Critchley HO, Jabbour HN. Inflammatory pathways in endometrial disorders. Mol Cell Endocrinol. 2011;335(1):42-51. doi: 10.1016/j.mce.2010.08.006.

19. Kungurtseva EA, Darenskaya MA, Nemchenko UM, Leshchenko OYa. [Oropharyngeal biocenosis in women with chronic endometrial inflammation and reproductive disorders]. Infectious Diseases. 2019;17(4): 92-97. [Article in Russian].

20. Sidorova IS, Makarov IO, Unanyan AL, Vlasov RS, Karpov DV. [Pathogenesis and pathogenetically based therapy of chronic endometritis (Clinical lecture)].Obstetrics, Gynecology and Reproduction. 2010;3:21-24. [Article in Russian].

21. Nalaboff KM, Pellerito JS, Ben-Levi E. Imaging the endometrium: disease and normal variants. Radiographics. 2001 Nov-Dec;21(6):1409-24. doi: 10.1148/ radiographics.21.6.g01nv211409.

22. Kuznetsova AV. Khronicheskiǔ éndometrit [Chronic endometritis]. Arkh Patol. 2000 May-Jun;62(3):48-52. [Article in Russian].

23. Greenwood SM, Moran JJ. Chronic endometritis: morphologic and clinical observations. Obstet Gynecol. 1981 Aug;58(2):176-84. .

24. Bayer-Garner IB, Korourian S. Plasma cells in chronic endometritis are easily identified when stained with syndecan-1. Mod Pathol. 2001 Sep;14(9):877-9. doi: 10.1038/ modpathol.3880405.

25. Kasius JC, Fatemi HM, Bourgain C, Sie-Go DM, Eijkemans RJ, Fauser BC, Devroey P, Broekmans FJ. The impact of chronic endometritis on reproductive outcome. Fertil Steril. 2011;96(6):1451-6. doi: 10.1016/j.fertnstert.2011.09.039.

26. Smith M, Hagerty KA, Skipper B, Bocklage T. Chronic endometritis: a combined histopathologic and clinical review of cases from 2002 to 2007. Int J Gynecol Pathol. 2010 Jan;29(1):44-50. doi: 10.1097/PGP.0b013e3181ae81bb.

27. Inoue T, Moran I, Shinnakasu R, Phan TG, Kurosaki T. Generation of memory $B$ cells and their reactivation. Immunol Rev. 2018 May;283(1):138-149. doi: 10.1111/imr.12640.

28. Hoyer BF, Radbruch A. Protective and pathogenic memory plasma cells. Immunol Lett. 2017 Sep;189:10-12. doi: 10.1016/j. imlet.2017.04.014. Epub 2017 Apr 25.

29. Kolesnikova LI, Grebenkina LA, Darenskaya MA, Vlasov BYa. [Oxidative stress as nonspecific pathogenetic link of reproductive disorders (systematic review)]. Bulletin of the Siberian Branch of the Russian Academy of Medical Sciences. 2012;32(1):58-66. [Article in Russian].

30. Kozlov VA. [Selection of cells in the thymus and homeostatic cell proliferation in the periphery during infectious processes]. Infection and Immunity. 2019;9(5-6):629-638. [Article in Russian].

31. Trunova LA, Gorbenko OM, Shvayuk AP, Obukhova OO, Trunov AN. [Features of the immune response in pubertal girls with chronic infectious and inflammatory diseases of the pelvic organs in remission]. International Journal on Immunorehabilitation. 2010;12(2):93-96. [Article in Russian]. 32. Moskalev AV, Sboychakov VB, Rudoy AS. General immunology with the basics of clinical immunology. Moscow; 2015:352. [In Russian].

33. Joyce S. Natural T cells: cranking up the immune system by prompt cytokine secretion. Proc Natl Acad Sci U S A. 2000 Jun 20;97(13):6933-5. doi: 10.1073/pnas.97.13.6933.

34. Yarilin AA. Immunology: textbook. M.: GEOTAR-Media. 2010:749. [In Russian].

35. Johnston-MacAnanny EB, Hartnett J, Engmann LL, Nulsen JC, Sanders MM, Benadiva CA. Chronic endometritis is a frequent finding in women with recurrent implantation failure after in vitro fertilization. Fertil Steril. 2010 Feb;93(2):437-41. doi: 10.1016/j.fertnstert.2008.12.131.

36. Danusevich I.N. [Cytokine-hormonal interactions in chronic endometritis in women with reproductive disorders]. Voprosy Ginekologii Akusherstva i Perinatologii. 2015;14(4):42-48. [Article in Russian].

37. Wira CR, Rossoll RM. Oestradiol regulation of antigen presentation by uterine stromal cells: role of transforming growth factor-beta production by epithelial cells in mediating antigenpresenting cell function. Immunology. 2003 Jul;109(3):398406. doi: 10.1046/j.1365-2567.2003.01670.x.

38. Herath S, Fischer DP, Werling D, Williams EJ, Lilly ST, Dobson H, et al. Expression and function of Toll-like receptor 4 in the endometrial cells of the uterus. Endocrinology. 2006 Jan;147(1):562-70. doi: 10.1210/en.2005-1113.

39. Tanikawa M, Acosta TJ, Fukui T, Murakami S, Korzekwa A, Skarzynski DJ, et al. Regulation of prostaglandin synthesis

*Corresponding author: Irina N. Danusevich, MD, PhD. Scientific Centre for Family Health and Human Reproduction Problems, Irkutsk, the Russian Federation. E-mail. irinaemails@ gmail.com 
by interleukin-1alpha in bovine endometrium during the estrous cycle. Prostaglandins Other Lipid Mediat. 2005 Dec;78(14):279-90. doi: 10.1016/j.prostaglandins.2005.09.003.

40. Simbirtsev AS. Cytokines: classification and biological functions. [Cytokines and Inflammation]. 2004; 3(2):16-22. [Article in Russian].

41. Kungurtseva EA, Belkova NL, Prefix AA, Ivanova EI, Darenskaya MA, Serdyuk LV, Leshchenko OYa. [The structure of opportunistic microbiota of nasopharynx and vaginal tract in women with reproduction disorders and chronic endometritis]. Russian Clinical Laboratory Diagnostics. 2017;62(4):252-256. [Article in Russian].

42. Bukharin OV. [From persistence to symbiosis of microorganisms]. Zhurnal Mikrobiologii, Epidemiologii i Immunobiologii. 2012;4:4-9. [Article in Russian].

43. Akira S, Uematsu S, Takeuchi O. Pathogen recognition and innate immunity. Cell. 2006 Feb 24;124(4):783-801. doi: 10.1016/j.cell.2006.02.015.

44. Beutler B. Inferences, questions and possibilities in Tolllike receptor signalling. Nature. 2004 Jul 8;430(6996):257-63. doi: 10.1038/nature02761.

45. Burger D, Dayer JM. Cytokines, acute-phase proteins, and hormones: IL-1 and TNF-alpha production in contact-mediated activation of monocytes by T lymphocytes. Ann N Y Acad Sci. 2002 Jun;966:464-73. doi: 10.1111/j.1749-6632.2002. tb04248.x.

46. Cole AM, Ganz T, Liese AM, Burdick MD, Liu L, Strieter RM. Cutting edge: IFN-inducible ELR- CXC chemokines display defensin-like antimicrobial activity. J Immunol. 2001 Jul 15;167(2):623-7. doi: 10.4049/jimmunol.167.2.623.

47. Fournier B, Philpott DJ. Recognition of Staphylococcus aureus by the innate immune system. Clin Microbiol Rev. 2005
Jul;18(3):521-40. doi: 10.1128/CMR.18.3.521-540.2005.

48. Wang JE, Jørgensen PF, Almlöf M, Thiemermann C, Foster SJ, Aasen AO, Solberg R. Peptidoglycan and lipoteichoic acid from Staphylococcus aureus induce tumor necrosis factor alpha, interleukin 6 (IL-6), and IL-10 production in both T cells and monocytes in a human whole blood model. Infect Immun. 2000 Jul;68(7):3965-70. doi: 10.1128/iai.68.7.3965-3970.2000. 49. Terzieva VI, Popova DN, Elenkov II. IFN- $\gamma$ Attenuates Spontaneous Lymphocyte Proliferation by Fuelling Regulatory T Cells in HIV-1-Infected Patients. Viral Immunol. 2017 Apr;30(3):157-166. doi: 10.1089/vim.2016.0075.

50. ContiP,DiGioacchinoM.MCP-1 andRANTESaremediators of acute and chronic inflammation. Allergy Asthma Proc. 2001 May-Jun;22(3):133-7. doi: 10.2500/108854101778148737.

51. Zhu D, Yang DY, Guo YY, Zheng YF, Li JL, Wang B, et al. Intracameral interleukin $1 \beta, 6,8,10,12 \mathrm{p}$, tumor necrosis factor $\alpha$ and vascular endothelial growth factor and axial length in patients with cataract. PLoS One. 2015 Feb 13;10(2):e0117777. doi: 10.1371/journal.pone.0117777.

52. Tagashira Y, Taniguchi F, Harada T, Ikeda A, Watanabe A, Terakawa N. Interleukin-10 attenuates TNF-alpha-induced interleukin-6 production in endometriotic stromal cells. Fertil Steril. 2009 May;91(5 Suppl):2185-92. doi: 10.1016/j. fertnstert.2008.04.052.

53. Marth CD, Firestone SM, Glenton LY, Browning GF, Young ND, Krekeler N. Oestrous cycle-dependent equine uterine immune response to induced infectious endometritis. Vet Res. 2016 Nov 8;47(1):110. doi: 10.1186/s13567-016-0398-x.

54. Medvedeva PA, Dzhioev YuP, Popkova SM, Danusevich IN. [The structure of species diversity of lactobacilli from the vaginal biotope of women living in Irkutsk]. Izvestia Irkutsk State University, 2012;5(1):11-17. [Article in Russian]. 